\title{
Effects of Nonketotic Streptozotocin Diabetes on Apolipoprotein B Synthesis and Secretion by Primary Cultures of Rat Hepatocytes
}

\author{
Janet D. Sparks, * Charles E. Sparks, * Mary Bolognino," Angela M. Roncone, ${ }^{\star}$ Timothy K. Jackson, ${ }^{\ddagger}$ and John M. Amatruda \\ ${ }^{*}$ Department of Pathology and Laboratory Medicine, and the ${ }^{\ddagger}$ Endocrine-Metabolism Unit, Department of Medicine, \\ University of Rochester School of Medicine and Dentistry, Rochester, New York 14642
}

\begin{abstract}
The effects of hypoinsulinemic nonketotic streptozotocin diabetes on hepatic apo $B$ synthesis and secretion was studied in primary cultures of rat hepatocytes. Diabetic rats were characterized by their significantly elevated serum glucose, apo B, and triglyceride levels, while serum insulin levels were less than a third of normal. Serum transaminase activities of diabetic rats were significantly elevated when compared with control rats, which was attributed to an increase in liver transaminase activity in diabetic rats. The pattern of enzyme activities of hepatocytes reflected that observed in livers of donor rats and the pattern was retained by primary cultures of hepatocytes over the culture period. Hepatocytes from diabetic rats secreted only one third of the apo B secreted by hepatocytes from control rats, which was determined by monoclonal immunoassay of rat total apo B. Decreases in secretion were confirmed by measurement of secretory $\left[{ }^{35}\right.$ S]methionine-labeled lipoprotein apo B radioactivity. The decreased apo B content of media of hepatocytes from diabetic rats was not due to increased apo B catabolism since hepatocytes from diabetic rats were shown to degrade less lipoprotein-apo $B$ than hepatocytes from normal rats in control experiments. In addition, the apo B content of detergent-solubilized hepatocytes from diabetic rats was significantly less than that of hepatocytes from control rats. These results suggest that insulin is necessary for normal hepatic apo B synthesis and secretion and that the hyperlipidemia associated with hypoinsulinemia in vivo is primarily of intestinal origin.
\end{abstract}

\section{Introduction}

Hyperlipidemia has been associated with human diabetes mellitus $(1,2)$ and with animal models of experimental diabetes (3-5), and is characterized by elevations of plasma apo B-containing lipoproteins. The atherogenic potential of such proteins (6) is consistent with the fact that diabetes is considered a significant risk factor for complications arising from premature atherosclerosis (7). The primary mechanism responsible for the hyperlipidemia has been the subject of recent

Address all correspondence to Dr. Janet D. Sparks, Department of Pathology and Laboratory Medicine, Box 608, University of Rochester School of Medicine and Dentistry, 601 Elmwood Avenue, Rochester, NY 14642.

Received for publication 15 April 1987 and in revised form 13 January 1988.

J. Clin. Invest.

(c) The American Society for Clinical Investigation, Inc.

0021-9738/88/07/0037/07 \$2.00

Volume 82 , July $1988,37-43$ reports that indicate the importance of intestinal lipoproteins $(4,5)$ and of defects in peripheral and hepatic catabolism of triglyceride-rich lipoproteins (TRL) ${ }^{1}$ and LDL through insulin-dependent processes (8-11). Several studies suggest that hepatically synthesized VLDL may contribute to the hyperlipoproteinemia associated with diabetes $(12,13)$. Other studies suggest that alterations in lipoprotein lipid content (14) and/or apolipoprotein composition (3-5) may be due to abnormal lipoprotein metabolism in diabetes and that these changes in composition may, in turn, influence subsequent catabolic events. To evaluate how hepatic apo B metabolism is affected by chronic hypoinsulinemia in vivo we undertook studies using primary cultures of hepatocytes from rats with nonketotic streptozotocin-induced diabetes. Primary cultures of hepatocytes are well suited for these studies since apo B secretory pathways can be evaluated without the complicating hormonal and substrate changes which are present in vivo. Our studies demonstrate that chronic hypoinsulinemia in vivo severely limits apo B synthesis and secretion by corresponding cultures of rat hepatocytes and suggest that normal lipoprotein B synthesis and secretion is dependent upon basal levels of endogenous insulin. These results support the concept that the hyperlipidemia and increased plasma apo B observed in streptozotocin diabetic rats is primarily of intestinal origin and is a result of a catabolic defect.

\section{Methods}

Animals. Male Sprague-Dawley rats fed ad lib. and weighing $200-280 \mathrm{~g}$ were used in all studies. Diabetes was induced by the injection of streptozotocin $(85 \mathrm{mg} / \mathrm{kg}$ ) (15). Rats were bled by tail vein 6-20 d after streptozotocin injection and serum was prepared. Serum glucose was estimated by a glucose oxidase method (16); serum insulin (17) and apo B (18) were measured by RIA; cholesterol was estimated by a cholesterol oxidase method (19) and triglyceride by glycerol assay after enzymatic hydrolysis (20). Serum alanine aminotransferase (ALT) (21), aspartate aminotransferase (AST) (21), and lactate dehydrogenase (LD) were also determined (22). Rats were used for hepatocyte preparation 6-20 d after streptozotocin injection and none of the rats used had positive urine ketones using Ames Keto-Diastix.

Preparation of hepatocytes for primary culture. Hepatocytes were prepared for primary culture in serum-free media (23) and placed onto $60-$ or $100-\mathrm{mm}$ sterile petri dishes coated with rat tail collagen $(100$ $\mu \mathrm{g} / \mathrm{ml}$ ). The dishes were incubated for $4 \mathrm{~h}$ at $37^{\circ} \mathrm{C}$ in an atmosphere of 95\% air/5\% $\mathrm{CO}_{2}$, after which the medium and nonadherent cells were discarded and adherent cells were washed three times with $2.0 \mathrm{ml}$ of 10 $\mathrm{mM}$ sodium phosphate, $\mathrm{pH} 7.4,139 \mathrm{mM}$ sodium chloride, and $0.1 \%$, wt/vol, BSA. Fresh media ( $2 \mathrm{ml} / 60-\mathrm{mm}$ dish and $3 \mathrm{ml} / 100-\mathrm{mm}$ dish)

1. Abbreviations used in this paper: ALT, alanine aminotransferase; apo $B_{H}$, apo $B$ of higher molecular weight; apo $B_{L}$, apo $B$ of lower molecular weight; AST, aspartate aminotransferase; LD, lactate dehydrogenase; TRL, triglyceride-rich lipoprotein. 
containing $0.2 \%, \mathrm{wt} / \mathrm{vol}, \mathrm{BSA}$ was then added and cells were incubated overnight. At the conclusion of experiments and after the removal of media, cellular protein was determined $(15,23)$. Cell viability was determined directly on plates containing hepatocytes after washing them in PBS by staining with Trypan blue (Sigma Chemical Co., St. Louis, MO). For apolipoprotein synthetic studies, media contained $100 \mu \mathrm{Ci} /$ plate $\left[{ }^{35} \mathrm{~S}\right]$ methionine $(1,405 \mathrm{Ci} / \mathrm{mmol})$.

Preparation of cellular homogenates. Cells from 5-10 plates were rinsed five times with fresh media and scraped into $2.0 \mathrm{ml}$ of ice-cold $0.05 \mathrm{M}$ barbital buffer, $\mathrm{pH} 8.6$, using a rubber policeman. The homogenizing buffer contained $0.5 \%$ Triton X-100, $0.15 \mathrm{M} \mathrm{NaCl}, 2.5 \mathrm{mM}$ EDTA, $2 \mathrm{mM}$ benzamidine, and $1 \mathrm{mM} \alpha$-toluene sulfonyl fluoride. Each plate was washed twice with $2.0 \mathrm{ml}$ of homogenizing buffer to completely transfer cells, after which the mixture was sonicated, and debris and nonsolubilized material was removed by centrifugation at $100,000 \mathrm{~g}$ at $4^{\circ} \mathrm{C}$ for $30 \mathrm{~min}$ as described by Patsch et al. (24). Cellular ALT, AST (21), and LD activities (21, 22), and protein (25) were determined immediately after centrifugation and dilution of the solubilized material in saline. Whole livers of control and diabetic rats were perfused in situ for $10 \mathrm{~min}$ via the portal vein using PBS and then $1 \mathrm{~g}$ of liver was dispersed in homogenizing buffer using a Polytron (Brinkmann Instruments Co., Westbury, NY). Debris and nonsolubilized material was removed by centrifugation as described above before dilution with saline.

Analytical procedures. The apo B content of media and detergentsolubilized cell extracts of hepatocytes were assayed using a single MAb solid phase RIA (18). The antibody used was a ${ }^{125}$ I-labeled mouse MAb equally reactive against rat apo $B$ of higher molecular weight $\left(a p o B_{H}\right)$ and rat apo $B$ of lower molecular weight (apo $B_{L}$ ). Standard dilutions (2.5-100 ng of apo B) were prepared from rat VLDL diluted in PBS containing $1 \% \mathrm{wt} / \mathrm{vol}, \mathrm{BSA}$, in media or in $0.5 \%$, vol/vol, Triton $\mathrm{X}-100 / 0.05 \mathrm{M}$ barbital buffer, $\mathrm{pH}$ 8.6. The apo B content of rat VLDL $(d<1.006 \mathrm{~g} / \mathrm{ml})$ was estimated from densitometric scans of gels of delipidated apolipoproteins separated by SDS-PAGE (26) and stained with Coomassie Blue (27) using the protein concentration of VLDL estimated by the dye-binding method, which also employed Coomassie Blue (25). Media lipoproteins were isolated by ultracentrifugation at salt densities of $1.063 \mathrm{~g} / \mathrm{ml}$ and between 1.063 and $1.21 \mathrm{~g} / \mathrm{ml}$ by the addition of solid sodium bromide as previously described (28). For control catabolic studies, lipoproteins were isolated at $d<1.006 \mathrm{~g} / \mathrm{ml}$ for TRL and at $1.019<d<1.063 \mathrm{~g} / \mathrm{ml}$ for LDL from sera of nonfasted control rats by ultracentrifugation, and the lipoproteins were radioiodinated using a modified iodine monochloride procedure (29). The apo B specific activities of TRL and LDL that were used for the control studies were 22 and $54 \mathrm{dpm} / \mathrm{ng}$, respectively. TCA precipitation was carried out as described previously (30). Alcohol precipitation of apo B of $\left[{ }^{35} S\right]$ methionine-labeled lipoproteins that were isolated by ultracentrifugation, and of media ${ }^{125} \mathrm{I}$-labeled apo B in control studies was carried out as described by Egusa et al. (31) after the addition of 50-100 $\mu \mathrm{g}$ of human LDL as carrier. Lipoproteins isolated by ultracentrifugation of culture media were dialyzed against $2.5 \mathrm{mM}$ EDTA and $1 \mathrm{mM} \alpha$-toluene sulfonyl fluoride at $4^{\circ} \mathrm{C}$ for $2-3 \mathrm{~h}$. After dialysis, 1 $\mathrm{mg}$ of Dextran T- 500 was added, the lipoproteins were delipidated, and apolipoproteins were dissolved in SDS buffer and separated by electrophoresis on gradient polyacrylamide gels (3.5-24\% acrylamide) (26) using Acrylaide and GelBond PAGE film (FMC Corp., Rockland, $\mathrm{ME}$ ). For catabolic studies $1.0 \mathrm{ml}$ of media containing ${ }^{125} \mathrm{I}$-labeled lipoproteins were delipidated, dissolved in SDS buffer, and electrophoresed as above. Gels containing $\left[{ }^{35} S\right]$ methionine-labeled apolipoproteins were stained and destained in Coomassie Blue (27), agitated for 4 $\mathrm{h}$ in $1 \%$ (vol/vol) glycerol, and then in Autofluor (National Diagnostics, Inc., Somerville, NJ) overnight. Enhanced gels and gels containing ${ }^{125} \mathrm{I}$-label were heat-fixed in a $95^{\circ} \mathrm{C}$ forced air oven for $30 \mathrm{~min}$. Dried gels were placed directly in contact with preflashed Kodak x-ray film, X-OMAT (XAR) or X-OMAT K (XK-1), in a wafer rigid cassette using Cronex Lightning-Plus intensifying screens (E.I. DuPont and de Nemours and Co., Inc., Clifton, NJ). Autoradiographs were developed using an automatic processor.

\section{Results}

Characterization of the nonketotic streptozotocin diabetic rat. The effect of streptozotocin diabetes on rat serum parameters are presented in Table I. Diabetic rats were characterized by their significant hypoinsulinemia and associated hyperglycemia. Serum triglycerides were significantly elevated in diabetic rats which was consistent with elevations of serum apo B. Compared with control rats, serum AST and ALT were significantly elevated by diabetes whereas LD was within normal limits. To distinguish whether elevated serum transaminases were due to liver damage or if they reflected increased intracellular enzyme activity, we determined the enzyme activity of whole livers from control and diabetic rats. Whole livers were preperfused for $10 \mathrm{~min}$ to remove blood before homogenization and analysis. As seen in Table II, the content of ALT and AST (shown in international units per liter per milligram of cell protein) in livers of diabetic rats was significantly greater than that of controls whereas the content of LD (in international units per liter per milligram of cell protein) in livers from diabetic rats was similar to controls. The ratios of serum enzyme activity (in international units per liter) to corresponding liver enzyme activity (in international units per liter per milligram of cell protein) were relatively constant for control and diabetic rats, [ALT, 0.50 and 0.52; AST, 0.11 and 0.14 ; and $L D, 0.46$ and 0.44 , respectively]. These results suggest that the elevation of serum transaminase activities of diabetic rats was reflective of an increase in liver enzyme activity rather than due to liver damage.

To determine whether hepatocytes retained the characteristics of the liver in vivo, we compared liver enzyme patterns of control and diabetic rats with those from corresponding hepatocytes in primary culture (Table II). Enzyme activities of hepatocytes per milligram of cell protein were greater than those of whole liver. This may be reflective of the nonparenchymal cells contained in whole liver preparations. As seen in Table II, the enzyme activity pattern of hepatocytes from diabetic and control rats corresponded to that obtained from perfused livers.

Table I. Effect of Nonketotic Streptozotocin Diabetes in Rats on Serum Parameters

\begin{tabular}{lcc}
\hline \multicolumn{1}{c}{ Parameter } & Control rat & Diabetic rat \\
\hline Glucose $(m g / d l)$ & $192 \pm 16$ & $551 \pm 74^{*}$ \\
Insulin $(\mu U / m l)$ & $34 \pm 11$ & $7 \pm 4^{*}$ \\
Apo B $(\mu g / m l)$ & $115 \pm 39$ & $216 \pm 52^{*}$ \\
Cholesterol $(m g / d l)$ & $41 \pm 23$ & $60 \pm 17$ \\
Triglyceride $(m g / d l)$ & $60 \pm 38$ & $256 \pm 116^{*}$ \\
ALT $(I U / l i t e r)$ & $38 \pm 9$ & $99 \pm 28^{*}$ \\
AST $(I U / l i t e r$ & $73 \pm 13$ & $149 \pm 82^{*}$ \\
LD $(I U /$ liter $)$ & $253 \pm 152$ & $227 \pm 114$ \\
\hline
\end{tabular}

Nonfasted rats were tail bled 6-20 d after injection of $(85 \mathrm{mg} / \mathrm{kg})$ buffered streptozotocin (diabetic rats) or buffer alone (control rats). Serum was prepared and analyzed as described in Methods. Results are from nine control and nine diabetic rats and are expressed as the mean $\pm S D$.

* Significantly different from the control value at a probability level of at least $P<0.05$ (unpaired $t$ test). 
Table II. Enzyme Activities of Liver and Primary Cultures of Hepatocytes from Control and Diabetic Rats

\begin{tabular}{lcccc}
\hline \multicolumn{1}{c}{ Enzyme } & \multicolumn{2}{c}{ Control rats } & \multicolumn{2}{c}{ Diabetic rats } \\
\hline ALT & & & & \\
$\quad$ Liver & $n=6$ & $76 \pm 14$ & $n=3$ & $191 \pm 41^{*}$ \\
$\quad$ Hepatocytes & $n=6$ & $123 \pm 63$ & $n=4$ & $237 \pm 69^{*}$ \\
AST & & & & \\
$\quad$ Liver & $n=3$ & $664 \pm 91$ & $n=3$ & $1096 \pm 199^{*}$ \\
$\quad$ Hepatocytes & $n=6$ & $1521 \pm 187$ & $n=4$ & $2055 \pm 50^{*}$ \\
LD & & & & \\
$\quad$ Liver & $n=3$ & $553 \pm 61$ & $n=3$ & $519 \pm 108$ \\
Hepatocytes & $n=4$ & $758 \pm 254$ & $n=4$ & $531 \pm 139$ \\
& & & &
\end{tabular}

Primary cultures of hepatocytes from control and diabetic rats were cultured for $16 \mathrm{~h}$, detergent solubilized using $0.5 \%$ Triton X-100 containing buffer, and were assayed for enzyme content as described in Methods. Whole livers were preperfused for $10 \mathrm{~min}$ with PBS to remove residual plasma and $1 \mathrm{~g}$ was homogenized in $0.5 \%$ Triton $\mathrm{X}-100$ containing buffer using a Polytron. Nonsoluble material was removed by centrifugation at $100,000 \mathrm{~g}$ and enzyme activity was determined on dilutions of the supernatants as described in Methods. Results are expressed as the mean activity (in international units per liter) per milligram of solubilized protein \pm SD.

* Significantly different from control value at a probability level of at least $P<0.05$ (unpaired $t$ test).

Viability of hepatocytes of control and nonketotic diabetic rats. Because differences in hepatic lipoprotein secretion could relate to inherent differences in collagenase dispersion of livers from control and diabetic rats and in their subsequent viability, it was important to determine if hepatocytes isolated from control and diabetic rats were equally viable in primary culture. Collagenase-dispersed hepatocytes from control and diabetic rats were plated onto $60-\mathrm{mm}$ dishes and hepatocellular enzyme activities were measured after cells adhered to culture dishes (initial) and after $21 \mathrm{~h}$ of incubation. We reasoned that the ability of cells to maintain cellular enzymes in culture was consistent with cell viability. As seen in Table III, hepatocytes from control and diabetic rats maintained cellular enzyme activities during the 21-h culture period. At the end of the incubation period media enzyme activities (in international units per milligram of cell protein per hour) represented $<1 \%$ of the total cellular transaminase activity (ALT, AST) and $<2 \%$ of the total cellular LD in both hepatocyte preparations from control and diabetic rats. Greater than $95 \%$ of the hepatocytes from control and diabetic rats were unstained by Trypan blue after $21 \mathrm{~h}$ in culture. The above results provide evidence that hepatocytes retain the adaptive enzyme patterns of the donor rat during the culture period, that cells do not leak excessive enzymes into the culture media, and that the cells from diabetic rats appear to be equally viable as those isolated from control rats.

Effect of diabetes on apo $B$ secretion and cellular apo $B$. To evaluate apo B secretion, hepatocytes from control and diabetic rats were cultured for $16 \mathrm{~h}$ after which the media was changed and the cells were incubated for an additional $5 \mathrm{~h}$. Media apo B concentration was determined by monoclonal immunoassay of the 5-h media. Because we used both 60 - and 100-mm dishes, we measured apo B secretion into the media under both culture conditions (Table IV). Hepatocytes from
Table III. The Effect of Duration of Culture on Enzyme Content of Hepatocytes from Control and Diabetic Rats

\begin{tabular}{llcc}
\hline & \multicolumn{3}{c}{ Enzyme activity } \\
\cline { 2 - 4 } & ALT & AST & LD \\
\hline & \multicolumn{3}{c}{ IUlliter per mg cell protein } \\
Hepatocytes from control rats & & & \\
$\quad \begin{array}{llll}\text { Initial cultures } \\
\text { 21-h cultures }\end{array}$ & $106 \pm 28$ & $1,254 \pm 294$ & $890 \pm 213$ \\
$\begin{array}{l}\text { Hepatocytes from diabetic rats } \\
\text { Initial cultures }\end{array}$ & $136 \pm 13$ & $1,443 \pm 127$ & $1,006 \pm 56$ \\
$21-h$ cultures & $251 \pm 6$ & $2,054 \pm 140$ & $733 \pm 12$ \\
& $293 \pm 39$ & $2,022 \pm 181$ & $698 \pm 35$ \\
\hline
\end{tabular}

Collagenase-dispersed hepatocytes from control and diabetic rats were plated onto $60-\mathrm{mm}$ collagen coated dishes and cells were allowed to adhere for $3 \mathrm{~h}$. Afterwards the plates were washed three times with media and the enzyme content of some of the plates was measured (initial cultures). Fresh media was added to the remaining plates and the cells were reincubated for an additional $21 \mathrm{~h}(21-\mathrm{h}$ cultures). Results are from triplicate plates and are expressed as enzyme activity (international units per liter) per milligram cell protein \pm SD.

diabetic rats secreted only 37 and $34 \%$ of the apo B secreted by hepatocytes from control rats using 60 - and $100-\mathrm{mm}$ collagencoated plates, respectively. Secretion rates ranged from 44 to $53 \mathrm{ng}$ apo $\mathrm{B} / \mathrm{mg}$ cell protein per $\mathrm{h}$ and from 16 to $20 \mathrm{ng}$ apo $B / m g$ cell protein per $h$ for hepatocytes from control and diabetic rats, respectively. Apo B secretion was not significantly different using $60-$ or $100-\mathrm{mm}$ plates and results consistently demonstrated reduced apo $B$ concentration in the media of hepatocytes from diabetic rats. Cellular apo B, as measured in

Table IV. The Effect of Nonketotic Streptozotocin Diabetes on Media Apo B Secretion and Cellular Apo B in Primary Cultures of Rat Hepatocytes

\begin{tabular}{cccc}
\hline & Protein & Media apo B & Cellular apo B \\
\hline & $m g /$ plate & \multicolumn{2}{c}{$n g / m g$ protein } \\
Control hepatocytes & & & \\
$n=4,60$-mm plates & $1.0 \pm 0.2$ & $266 \pm 16$ & $341 \pm 81$ \\
$n=5,100$-mm plates & $4.9 \pm 1.1$ & $241 \pm 46$ & $\mathrm{ND}$ \\
Diabetic hepatocytes & & & \\
$n=4,60$-mm plates & $0.8 \pm 0.2$ & $99 \pm 32^{*}$ & $128 \pm 29^{\ddagger}$ \\
$n=5,100$-mm plates & $5.5 \pm 0.4$ & $83 \pm 17^{*}$ & $\mathrm{ND}$ \\
& & & \\
\hline
\end{tabular}

Hepatocytes from control and diabetic rats were plated onto $60-\mathrm{mm}$ or 100 -mm collagen-coated plates. After culturing the hepatocytes for $16 \mathrm{~h}$, culture media was changed and the incubation was continued for $5 \mathrm{~h}$. Media was collected and cellular and media apo B concentrations were determined by monoclonal RIA. Media apo B values are expressed as the mean of the average of 5-10 plates assayed individually from four or five separate liver preparations \pm SEM. Cellular apo B values were determined on a pool of 10 plates of solubilized hepatocytes from three separate liver preparations. * Significantly different from the control value using an unpaired $t$ test, at a probability level of at least $P<0.02$.

‡ Significantly different from the control value using the Mann-Whitney test for significance, $P<0.05$. 
detergent-solubilized cell extracts by monoclonal immunoassay, was similarly $(37.5 \%)$ reduced in hepatocytes of diabetic rats compared with that of control rats in $60-\mathrm{mm}$ culture dishes (Table IV). The apo B content of sequential density fractions $(d<1.063 \mathrm{~g} / \mathrm{ml}$ and $1.063<d<1.021 \mathrm{~g} / \mathrm{ml})$ isolated by ultracentrifugation was also measured (Table $\mathrm{V}$ ) and was significantly reduced in hepatocyte media from diabetic rats compared with that of controls.

Effect of diabetes on secretion of newly synthesized apo $B$. To compare the secretion of newly synthesized apo $B$ with that of total apo B, hepatocytes from control and diabetic rats were incubated with media containing $\left[{ }^{35} S\right]$ methionine. After $16 \mathrm{~h}$ the media was removed, $d<1.063 \mathrm{~g} / \mathrm{ml}$ lipoproteins were isolated, and apo B was precipitated in aqueous 2-propanol as described in Methods. The percentage of $\left[{ }^{35}\right.$ S $]$ methionine lipoprotein label that were recovered in apo B precipitates was (mean \pm SD [number of liver preparations]) $30.1 \pm 4.3 \%(n=4)$ of lipoproteins secreted by hepatocytes from control rats and $10.6 \pm 1.1 \%(n=3)$ of lipoproteins secreted by hepatocytes from diabetic rats. Labeled lipoproteins were delipidated, separated by SDS-PAGE, and visualized by fluorography after gel enhancement. As seen in Fig. 1, apo $B_{H}$, apo $B_{L}$, apo $E$, and apo $\mathrm{C}$ proteins of control and diabetic lipoproteins were labeled, and there was significantly less ${ }^{35} \mathrm{~S}$-labeled apo $\mathrm{B}_{\mathrm{H}}$, apo $B_{L}$, and apo $E$ secreted by hepatocytes from diabetic rats compared with the amount secreted by hepatocytes from control rats.

Control studies. Control studies were performed to determine whether the observed decrease in apo B secreted by hepatocytes from diabetic rats could be due to increased apo $B$ degradation in the media. A concentration of apo B approximately equivalent to that secreted into the culture media in $5 \mathrm{~h}$ was used to reflect experimental conditions as described in Table IV. Plasma ${ }^{125} \mathrm{I}$-TRL-apo B (190 ng apo B/ml media) and ${ }^{125} \mathrm{I}-\mathrm{LDL}$-apo $\mathrm{B}(140 \mathrm{ng} / \mathrm{ml}$ media) isolated from control rats were added to triplicate plates of hepatocytes from diabetic and control rats and were incubated for $16 \mathrm{~h}$. Separate triplicate plates from each condition were incubated for $15 \mathrm{~min}$ to

Table V. The Effect of Nonketotic Streptozotocin Diabetes on the Distribution of Apo B in Sequential Density Lipoprotein Fractions Secreted by Primary Cultures of Rat Hepatocytes

\begin{tabular}{lcc}
\hline & \multicolumn{2}{c}{ Lipoprotein apo B } \\
\cline { 2 - 3 } & $d<1.063 \mathrm{~g} / \mathrm{ml}$ & $1.063<d<1.21 \mathrm{~g} / \mathrm{ml}$ \\
\hline \multicolumn{2}{c}{$n g / m g$ cell protein } \\
Control media & \multicolumn{2}{c}{$60 \pm 15^{*}$} \\
Diabetic media & $115 \pm 7$ & $15 \pm 4^{*}$ \\
& $44 \pm 7^{*}$ &
\end{tabular}

Hepatocytes from control and diabetic rats were cultured for $16 \mathrm{~h}$ after which the media was changed and the culture period continued for $5 \mathrm{~h}$. Lipoprotein fractions of $d<1.063 \mathrm{~g} / \mathrm{ml}$ and $1.063<d$ $<1.21 \mathrm{~g} / \mathrm{ml}$ were isolated by sequential density ultracentrifugation of media from the 5-h cultures. After isolation, the fractions were dialyzed and the apo B concentration of each fraction estimated by monoclonal immunoassay. Results are expressed as the mean of pooled media from four pools of nine $100-\mathrm{mm}$ culture plates $\pm S D$. * Significantly different from the control value at a probability level of at least $P<0.05$ (unpaired $t$ test).

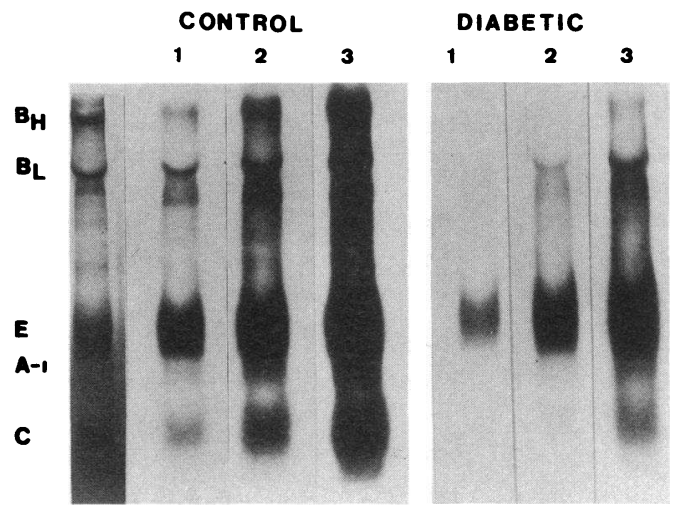

Figure 1. Fluorograph of $\left[{ }^{35} \mathrm{~S}\right]$ methionine-labeled apolipoproteins of $d<1.063 \mathrm{~g} / \mathrm{ml}$ lipoproteins secreted by hepatocytes of control and diabetic rats in 16-h cultures. After the media was exposed to $\left[{ }^{35} \mathrm{~S}\right]-$ methionine for $16-\mathrm{h}$, it was extensively dialyzed against $0.01 \mathrm{M}$ methionine buffer, $\mathrm{pH} 7.0$, and lipoproteins that were isolated by ultracentrifugation after adjustment of salt densities to $1.063 \mathrm{~g} / \mathrm{ml}$. Labeled lipoproteins were dialyzed briefly and delipidated. Apolipoproteins were dissolved in SDS buffer and separated by SDS-PAGE. Gels were stained, enhanced, heat fixed, and fluorographed. In the figure, labeled apolipoproteins that were secreted by hepatocytes from control (middle) and diabetic rats (right) are compared to Coomassie Blue-stained apolipoproteins of rat plasma VLDL (left). The numbers on the top of each lane refer to days of exposure to the film.

act as the initial media control and degradation was calculated as the difference between the 15-min and 16-h samples. Using the TCA precipitation method, hepatocytes from control and diabetic rats degraded (mean \pm SD) $34.0 \pm 3.6$ and $20.4 \pm 1.3 \%$ of added total ${ }^{125} \mathrm{I}-\mathrm{TRL}$ label $(P<0.01)$, and $17.6 \pm 4.7$ and

Table VI. The Effect of Nonketotic Streptozotocin Diabetes on the Percentage of ${ }^{125}$ I-Apo B Degraded by Hepatocyte Cultures from Control and Diabetic Rats in $16 \mathrm{~h}$

\begin{tabular}{|c|c|c|c|c|}
\hline \multirow[b]{2}{*}{ Method } & \multicolumn{2}{|c|}{${ }^{125}$ I-TRL } & \multicolumn{2}{|c|}{${ }^{125}$ I-LDL } \\
\hline & Control rat & Diabetic rat & Control rat & Diabetic rat \\
\hline $\begin{array}{l}\text { 2-Propanol } \\
\text { precipitation* }\end{array}$ & $27.4 \pm 2.5$ & $9.2 \pm 1.8^{5}$ & $20.4 \pm 1.5$ & $6.7 \pm 3.7^{\S}$ \\
\hline SDS-PAGE & $26.8 \pm 14.1$ & $16.0 \pm 11.9$ & $33.1 \pm 10.8$ & $8.0 \pm 2.5^{8}$ \\
\hline
\end{tabular}

Hepatocytes from control and diabetic rats were cultured for $15 \mathrm{~min}$ and $16 \mathrm{~h}$ in the presence of added ${ }^{125} \mathrm{I}-\mathrm{TRL}$ (190 $\mathrm{ng}$ apo B/ml) and ${ }^{125} \mathrm{I}-\mathrm{LDL}$ ( $140 \mathrm{ng}$ apo B/ml) prepared from sera of nonfasted control rats. Three plates of hepatocytes were prepared and analyzed for each condition. The protein content of each plate was assayed and was $1.6 \pm 0.19$ and $1.6 \pm 0.21 \mathrm{mg}$ for hepatocytes of control and diabetic rats, respectively.

* Apo B degradation was calculated from the loss of 2-propanol precipitable radioactivity of the 15 -min and 16-h media and results are presented as the mean percent degraded \pm SD for triplicate plates. ₹ Apo B degradation was calculated from the loss of radioactivity of SDS-PAGE gel slices containing apo $B_{H}$ and apo $B_{L}$ bands of the 15min and 16-h media and results are expressed as the mean percent degraded \pm SD for triplicate plates.

'Significantly different from the control value at a probability level of at least $P<0.05$ (unpaired $t$ test). 
9.2 $\pm 3.3 \%$ of added total ${ }^{125} \mathrm{I}-\mathrm{LDL}$ label $(P<0.06)$, respectively. Apo B degradation was quantitated by 2-propanol precipitation, by SDS-PAGE and gel slicing, and the results are summarized in Table VI. Using the alcohol precipitation method, hepatocytes of diabetic rats degraded significantly less apo B of TRL and LDL than controls. Autoradiographs of SDS gels of the media are seen in Fig. 2 and were used to locate apo B bands that were cut out in their entirety for radioassay. The difference in apo B radioactivity of the 15-min and 16-h samples was used to calculate the percent of degraded apo B (Table VI). Using the SDS-PAGE and gel slicing method, results were more variable but consistent with the alcohol precipitation results. These control experiments demonstrate that the observed decrease in media apo B secreted by hepatocytes of diabetic rats was not due to increases in apo $\mathrm{B}$ degradation.

\section{Discussion}

The model of nonketotic diabetes in rats, which is induced by injection of streptozotocin, is characterized by hypoinsulinemia and hyperglycemia with associated hypertriglyceridemia and elevations of apo B-containing lipoproteins consistent with previous reports $(3-5,13)$. In diabetic rats, serum and liver transaminases are elevated, which possibly indicates an adaptive increase in diabetes that is consistent with enhancement of gluconeogenic pathways. The enzyme pattern of hepatocytes in primary culture parallels patterns of corresponding intact livers, which supports the idea that primary cultures of hepatocytes mirror the in vivo characteristics of the animal from which they were derived.

Because differences in hepatic metabolism observed in primary cultures of hepatocytes may relate to differences in longevity of the cultured cells in vitro, we evaluated the viability of hepatocytes from normal and diabetic rats in control cultures. Five lines of evidence support the idea that hepatocytes from diabetic rats were as viable as those from control rats in primary cultures. First, hepatocytes from diabetic rats had sig-

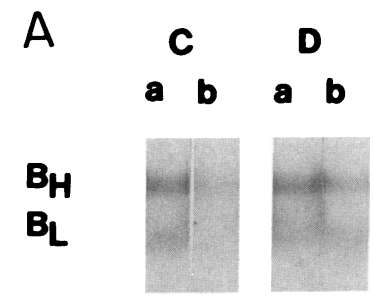

B

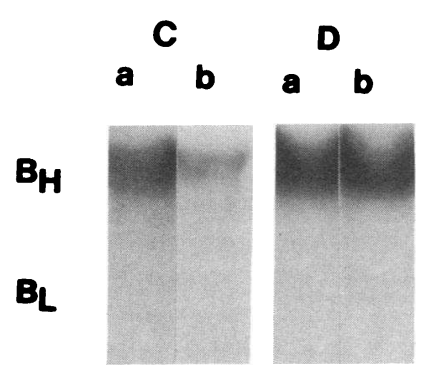

nificantly higher ALT and AST enzyme activities than hepatocytes from control rats. Second, hepatocytes from control and diabetic rats had a distribution of hepatic enzyme activity (ALT, AST, LD) similar to corresponding intact livers, which indicates that they retained the adaptive changes that occurred in vivo. Third, cellular enzyme activity was maintained in hepatocytes over $21 \mathrm{~h}$ of culture. Fourth, there was minimal cell leakage during incubation since culture media contained $<2 \%$ of the cellular enzyme activity. Fifth, $>95 \%$ of hepatocytes from control and diabetic rats that adhere to the collagen-coated dishes are capable of excluding Trypan blue.

In the current studies, hepatocytes of nonketotic streptozotocin diabetic rats secreted only one-third of the apo B secreted by hepatocytes from control rats with concomitant decreases in the apo B content of $d<1.063 \mathrm{~g} / \mathrm{ml}$ and $1.063<d$ $<1.21 \mathrm{~g} / \mathrm{ml}$ lipoprotein fractions. This finding was supported by stained gels (data not shown) and by results demonstrating that diabetic rats secreted less newly synthesized $\left(\left[{ }^{35} \mathrm{~S}\right]-\right.$ methionine labeled) apo $B_{H}$, apo $B_{L}$, and apo $E$ compared with that secreted by the hepatocytes of control rats. In addition to impaired lipoprotein-apo B secretion by hepatocytes from diabetic rats, the cellular apo B concentration of these cells was significantly reduced when compared with that of control cells. The apo B content of hepatocytes from control rats by monoclonal immunoassay $(18,26)$ was similar to that reported by Patsch et al. (24) who used polyclonal RIA. These data support the concept that in hypoinsulinemic diabetes there is an alteration of net apo B synthesis rather than an imbalance of synthesis, assembly, and secretion. The decrease in intracellular apo B in diabetics may result in a decrease in available apo B for lipoprotein assembly and may be the result of decreased synthesis or, alternatively, of increased intracellular apo B turnover.

In control experiments ${ }^{125} \mathrm{I}-\mathrm{TRL}$ and ${ }^{125} \mathrm{I}-\mathrm{LDL}$ from normal rats were added to hepatocytes from control and diabetic rats to test the hypothesis that increased apo B degradation in the media might have contributed to the apparently decreased apo $B$ concentration in media of hepatocytes from diabetic rats. Using 2-propanol precipitation, SDS-PAGE and gel slicing to assess apo $B$ degradation, hepatocytes from diabetic rats degraded significantly less lipoprotein-apo B than hepatocytes from control rats over $16 \mathrm{~h}$. This finding was confirmed by results obtained using TCA precipitation. Our studies demonstrated that $27 \%$ of TRL-apo B was degraded over $16 \mathrm{~h}$ by hepatocytes from control rats, which is in contrast to the results of Patsch et al. (24) who reported that $<15 \%$ of VLDL was degraded under similar culture conditions. Different results may be due to differences in the plating density, in the lipoprotein fractions used (TRL vs. VLDL), in apo $B_{H}$ and apo $B_{L}$ variant composition of the lipoprotein preparations (32), or to saturation effects of lipoproteins on hepatic catabolic pathways at the higher apo B concentrations used by Patsch et al. (24). Nevertheless, our results demonstrate that the decreased apo $B$ content of media of hepatocytes from diabetic rats is not a result of enhanced apo $B$ uptake and degradation by these cells.

Our results support and extend those of Berry et al. (33) who demonstrated a $40 \%$ decrease in secreted VLDL total apolipoprotein, apo E, triglyceride, and cholesterol mass, and a fivefold reduction, when compared with controls, in lipoprotein protein specific activity, which was derived from $\left[{ }^{3} \mathrm{H}\right]-$ 
leucine of 3-h perfusates of livers from diabetic rats. In our studies the apo B composition of secretory lipoproteins, as determined by aqueous 2-propanol precipitation of $\left[{ }^{35} \mathrm{~S}\right]$ methionine-labeled lipoproteins, was 30 and $11 \%$ of total newly synthesized apolipoproteins from control and diabetic rats, respectively, which was consistent with the known apo B content of nascent lipoproteins as determined in liver perfusion studies of control rats (34) and in apolipoprotein label incorporation studies of diabetic rat livers (33). As apo B is believed to be an obligatory component of $\operatorname{TRL}(35,36)$, our results demonstrate that hepatocytes of diabetic rats secrete fewer lipoprotein-apo B particles than normal rats. These results are consistent with the ultrastructural and functional studies of Reaven and Reaven (13) who demonstrated a significant decrease in the VLDL content of liver Golgi complexes and a decreased triglyceride entry rate in rats $7 \mathrm{~d}$ after streptozotocin injection.

Studies of plasma lipoproteins of streptozotocin diabetic rats have shown that plasma apo $B$ and triglyceride levels are significantly increased, while plasma apo E levels are decreased $(3,4)$. The current studies show hepatic lipoprotein secretion is severely impaired by hypoinsulinemia (approximately onethird normal) and secretory apo $\mathrm{E}$ as well as apo B are reduced. Our results, therefore, strongly support the idea that the observed increase in plasma apo B of streptozotocin diabetic rats in vivo is primarily of intestinal origin and is a result of a catabolic defect involving these lipoproteins. A defect in catabolic pathways that is shared by hepatic and intestinal apo B-containing lipoproteins would result in a combined form of hyperlipoproteinemia. Our studies further demonstrate that the catabolism of normal TRL and LDL is defective in the hepatocytes of diabetic rats which indicates that changes in lipoprotein apo E content alone could not account for the observed differences. These results suggest that there is an alteration of receptor-mediated apo $B$ degradation in diabetes. Particularly interesting is the decreased degradation of apo $B_{H}$ (Fig. 2), which suggests an alteration of LDL receptor-mediated processes in diabetics.

We $(26)$ and others $(24,37,38)$ have recently reported that high concentrations of insulin inhibit lipoprotein-apo B secretion by primary cultures of rat hepatocytes. Decreased hepatic triglyceride output in response to high portal insulin levels has been shown in human studies (12) to be consistent with the rat in vitro results. In light of the current findings it is necessary to postulate a dual role for insulin in hepatic apo B metabolism. The first is to maintain normal levels of cellular apo B synthesis, lipoprotein secretion, and catabolism on a chronic basis. The second is to acutely inhibit hepatic apo B synthesis and secretion at postprandial portal-vein insulin concentrations during chylomicron synthetic and lipolytic phases where rapid uptake of intestinal remnants by the liver occurs. As insulin levels fall during the interprandial period, hepatic VLDL secretion resumes, thereby balancing lipid delivery to peripheral tissues during the postprandial period.

\section{Acknowledgments}

We gratefully acknowledge the skilled technical assistance of Patricia A. Trax, Cindy L. Swicegood, and Douglas J. Pryce.

This investigation was supported by research grants HL-29837 and AM-20948 from the National Institutes of Health. Dr. Jackson is a recipient of a fellowship from the James $P$. Wilmot Cancer Research Fellowship Program, University of Rochester, Rochester, NY.

\section{References}

1. Reckless, J. P. D., D. J. Betteridge, P. Wu, B. Payne, and D. J. Galton. 1978. High-density and low-density lipoproteins and prevalence of vascular disease in diabetes mellitus. Br. Med. J. 1:883-886.

2. Nikkila, E. A. 1984. Plasma lipid and lipoprotein abnormalities in diabetes. In Diabetes and Heart Disease. R. J. Jarrett, editor. Elsevier Scientific Publishers BV/North Holland, Amsterdam. 134-167.

3. Bar-On, H., P. S. Roheim, and H. A. Eder. 1976. Serum lipoproteins and apolipoproteins in rats with streptozotocin-induced diabetes. J. Clin. Invest. 57:714-721.

4. O'Looney, P., D. Irwin, P. Briscoe, and G. V. Vahouny. 1985. Lipoprotein composition as a component in the lipoprotein clearance defect in experimental diabetes. J. Biol. Chem. 260:428-432.

5. Levy, E., E. Shafrir, E. Ziv, and H. Bar-On. 1985. Composition, removal and metabolic fate of chylomicrons derived from diabetic rats. Biochim. Biophys. Acta. 834:376-385.

6. Goldstein, J. L., and M. S. Brown. 1977. The low-density lipoprotein pathway and its relation to atherosclerosis. Annu. Rev. Biochem. 46:897-930.

7. Harris, M. I., and P. Entmacher. 1985. Diabetes in America. Mortality in Diabetes. U.S. Government Printing Office/Washington, DC. National Institutes of Health Publication 85-1468.

8. Nikkila, E. A., J. K. Huttunen, and C. Enholm. 1977. Postheparin plasma lipoprotein lipase and hepatic lipase in diabetes mellitus. Relationship to plasma triglyceride metabolism. Diabetes. 26:11-21.

9. Brunzell, J. D., D. Porte, and E. L. Bierman. 1979. Abnormal lipoprotein lipase mediated plasma triglyceride removal in untreated diabetes mellitus associated with hypertriglyceridemia. Metab. Clin. Exp. 28:901-907.

10. Goldberg, A. P., A. Chait, and J. D. Brunzell. 1980. Post-prandial adipose tissue lipoprotein lipase activity in primary hypertriglyceridemia. Metab. Clin. Exp. 29:223-229.

11. Chait, A., E. L. Bierman, and J. J. Albers. 1978. Regulatory role of insulin in the degradation of low density lipoprotein by cultured human skin fibroblasts. Biochim. Biophys. Acta. 529:292-299.

12. Vogelberg, K. H., F. A. Gries, and D. Moschinski. 1980. Hepatic production of VLDL-triglycerides. Dependence of portal substrate and insulin concentration. Horm. Metab. Res. 12:688-694.

13. Reaven, E. P., and G. M. Reaven. 1974. Mechanisms for the development of diabetic hypertriglyceridemia in streptozotocintreated rats. J. Clin. Invest. 54:1167-1178.

14. Schonfeld, G., C. Birge, J. P. Miller, G. Kessler, and J. Santiago. 1974. Apolipoprotein B levels and altered lipoprotein composition in diabetes. Diabetes. 23:827-834.

15. Salhanick, A. I., P. Konowitz, and J. M. Amatruda. 1983. Potentiation of insulin action by a sulfonylurea in primary cultures of hepatocytes from normal and diabetic rats. Diabetes. 32:206-212.

16. Trinder, P. 1969. Determination of blood glucose using an oxidase-peroxidase system with a non-carcinogenic chromogen. $J$. Clin. Pathol. (Lond.). 22:158-161.

17. Coat-a-Count Insulin, Diagnostic Products Corporation, Los Angeles, CA.

18. Sparks, J. D., M. Bolognino, P. A. Trax, and C. E. Sparks. 1986 The production and utility of monoclonal antibodies to rat apolipoprotein B lipoproteins. Atherosclerosis. 61:205-211.

19. Roschlau, P., E. Bernt, and W. Gruber. 1974. Enzymatic determination of cholesterol in serum. Z. Klin. Chem. Klin. Biochem. 12:403-407.

20. Bucolo, G., and H. David. 1973. Quantitative determination of serum triglycerides by the use of enzymes. Clin. Chem. 19:476-482.

21. Henry, R. J., N. Chiamori, O. J. Golub, and S. Berkman. 1960. Revised spectrophotometric methods for the determination of glu- 
tamic-oxalacetic transaminase, glutamic-pyruvic transaminase, and lactic acid dehydrogenase. Am. J. Clin. Pathol. 34:381-398.

22. Kinetic LDH AM Blue 610 LDH, American Monitor Corporation, Indianapolis, IN.

23. Amatruda, J. M., and C. L. Chang. 1983. The regulation of lipid synthesis in primary cultures of hepatocytes from non-ketotic streptozotocin diabetic rats. Metab. Clin. Exp. 32:224-229.

24. Patsch, W., S. Franz, and G. Schonfeld. 1983. Role of insulin in lipoprotein secretion by cultured rat hepatocytes. J. Clin. Invest. 71:1161-1174.

25. Bradford, M. M. 1976. A rapid and sensitive method for the quantitation of microgram quantitites of protein utilizing the principle of protein-dye binding. Anal. Biochem. 72:248-254.

26. Sparks, C. E., J. D. Sparks, M. Bolognino, A. Salhanick, P. S. Strumph, and J. M. Amatruda. 1986. Insulin effects on apolipoprotein B-lipoprotein synthesis and secretion by primary cultures of rat hepatocytes. Metab. Clin. Exp. 35:1128-1136.

27. Fairbanks, G., T. L. Steck, and D. F. H. Wallach. 1971. Electrophoretic analysis of the major polypeptides of the human erythrocyte membrane. Biochemistry. 10:2606-2617.

28. Hatch, F. T., and R. S. Lees. 1968. Practical methods for plasma lipoprotein analysis. Adv. Lipid Res. 6:1-68.

29. Bilheimer, D. W., S. Eisenberg, and R. I. Levy. 1972. The metabolism of very low density lipoproteins. I. Preliminary in vitro and in vivo observations. Biochim. Biophys. Acta. 260:212-221.

30. Sparks, C. E., J. L. De Hoff, D. M. Capuzzi, G. Pietra, and J. B.
Marsh. 1978. Proteolysis of very low density lipoprotein in perfused lung. Biochim. Biophys. Acta. 529:123-130.

31. Egusa, G., D. W. Brady, S. M. Grundy, and B. V. Howard. 1983. Isopropanol precipitation method for determination of apolipoprotein specific activity and plasma concentrations during metabolic studies of very low density lipoprotein and low density lipoprotein B. $J$. Lipid Res. 24:1261-1267.

32. Sparks, C. E., and J. B. Marsh. 1981. Metabolic heterogeneity of apolipoprotein B in the rat. J. Lipid Res. 22:519-527.

33. Berry, E. M., E. Ziv, and H. Bar-On. 1981. Lipoprotein secretion by isolated perfused livers from streptozotocin-diabetic rats. Diabetologia. 21:402-408.

34. Marsh, J. B., and C. E. Sparks. 1979. Hepatic secretion of lipoproteins in the rat and the effect of experimental nephrosis. J. Clin. Invest. 64:1229-1237.

35. Gotto, A. M., R. I. Levy, K. John, and D. S. Fredrickson. 1971. On the protein defect in abetalipoproteinemia. N. Engl. J. Med. 284:813-818.

36. Malloy, M. J., and J. P. Kane. 1982. Hypolipidemia. Med. Clin. N. Am. 66:469-484.

37. Durrington, P. N., R. S. Newton, D. B. Weinstein, and D. Steinberg. 1982. Effects of insulin and glucose on very low density lipoprotein triglyceride secretion by cultured rat hepatocytes. J. Clin. Invest. 70:63-73.

38. Patsch, W., A. M. Gotto, Jr., and J. R. Patsch. 1986. The effects of insulin on lipoprotein secretion in rat hepatocyte cultures. The role of the insulin receptor. J. Biol. Chem. 261:9603-9606. 